\title{
A IMPORTÂNCIA DA APLICAÇÃO DO DESENVOLVIMENTO SUSTENTÁVEL E dA EDUCAÇÃo AMBIENTAL NO CORPO DE BOMBEIROS DO PARANÁ
}

\section{ARTIGO ORIGINAL}

COSTA, Marcos Juliano da ${ }^{1}$

COSTA, Marcos Juliano da. A importância da aplicação do desenvolvimento sustentável e da educação ambiental no Corpo de Bombeiros do Paraná. Revista Científica Multidisciplinar Núcleo do Conhecimento. Ano 05, Ed. 01, Vol. 05, pp. 93113. Janeiro de 2020. ISSN: 2448-0959, Link de acesso: https://www.nucleodoconhecimento.com.br/meio-ambiente/importancia-daaplicacao

\section{RESUMO}

Este estudo tem o objetivo apontar, para gestores do Corpo de Bombeiros do Estado do Paraná, a necessidade da adoção de novas práticas que contribuam para o desenvolvimento sustentável, por meio de ações de Educação Ambiental e adaptações estruturais nos quartéis. Através de consultas bibliográficas, o trabalho sugere a aplicação de medidas capazes de reduzir os danos causados ao meio ambiente, além de demonstrar a necessidade de um órgão governamental com forte influência que coopere com a questão ambiental, tanto no ponto de conservação do meio ambiente como na inspiração para a população.

Palavras-Chave: Desenvolvimento sustentável, educação ambiental, Corpo de Bombeiros.

\footnotetext{
${ }^{1}$ Graduação em gestão financeira. Graduando em ciências contábeis, pós-graduação em direito administrativo. pós-graduação em gestão pública, pós-graduação em Saúde e qualidade de vida e pós-graduação em segurança pública.
} 


\section{INTRODUÇÃO}

O objetivo deste artigo é demonstrar a gestores do Corpo de Bombeiros do Estado do Paraná a necessidade de adotar novas práticas que contribuam com a sustentabilidade. O fomento desse trabalho partiu das ideias de Chievato, o qual explicita em sua obra Recursos Humanos que "O desenvolvimento sustentável leva a uma economia sustentável. A preservação e o aproveitamento racional dos recursos naturais são conseguidos pelo desenvolvimento sustentável, possibilitando a viabilidade da economia sustentável e dando ao homem um ambiente saudável". (1997, p.113).

Primeiramente este artigo explanará sobre alguns dos principais problemas ambientais globais e a conceituação de desenvolvimento sustentável. Na sequência ao trabalho expõe a necessidade de mudança agregado a propostas de práticas que proporcionam um direcionamento inicial em busca de um modelo que coopere com a sustentabilidade. Destas propostas podemos citar ações de Educação Ambiental e mudanças estruturais na Corporação que possam contribuir com a sustentabilidade. Foi também observado a possível influência na população com a adoção, por parte dos bombeiros, dessas novas atitudes - tendo em vista a excelente credibilidade depositada pela população na Corporação em questão.

A pesquisa utilizou-se diversas revisões bibliográficas, consultas de páginas eletrônicas e artigos que abordam o assunto. Reunindo, assim, informações necessárias sobre a importância da aplicação de meios que contribuam com a conservação do meio ambiente.

\section{PROBLEMAS AMBIENTAIS GLOBAIS}

O avanço conquistado pelo homem no último século é algo sem precedentes. Porém, veio acompanhado de uma série de problemas ambientais, causados principalmente pelos meios de produção e consumo adotados pela atual civilização. 
Lamentavelmente nosso planeta é afetado por vários acontecimentos e problemas ambientais, muitos deles provocados por diversas ações humanas. Estas questões de difíceis resoluções afetam a fauna, flora, solo, águas e ar, comprometendo diretamente o meio ambiente, e como consequências poluindo diretamente $0 \mathrm{ar}$, através de gases poluentes, poluição de rios, lagos mares e oceanos provocada por dejetos de esgotos, lixo, acidentes ambientais, como vazamento de petróleo, contaminação do solo provocada por (fertilizantes, e produtos químicos) e descarte muitas vezes incorreto de lixo, e outras situações que não são observadas, mas tem contribuído diretamente na degradação do meio ambiente que são os desmatamentos proveniente de corte ilegal de árvores para comercialização da matéria-prima.

Estatísticas mostram que os problemas ambientais comprometem o futuro da vida no planeta. Atualmente, a humanidade já consome $25 \%$ mais recursos naturais do que a Terra pode oferecer, segundo dados da organização não-governamental WWF, com base nos estudos sobre a Pegada Ecológica1.

Isso significa que é necessário um planeta e mais um quarto para sustentar o estilo de vida atual. Esta forma de exploração da natureza gera o esgotamento dos recursos naturais mais rápido do que a capacidade de renovação do planeta. É importante lembrar que este dado se refere à média de consumo mundial, ou seja, nem todos os habitantes do planeta têm o mesmo nível de consumo - muitos inclusive não consomem nem mesmo o mínimo para garantir a sobrevivência.

Este modelo de exploração dos recursos naturais causa uma perda significativa da biodiversidade. Segundo a WWF, entre os anos de 1970 e 2000 foi em torno de $35 \%$ - índice comparado a eventos de extinção em massa ocorridos cerca de cinco vezes durante bilhões de anos da história da Terra e causados por desastres naturais e não pela ação do homem como ocorre atualmente.

Além disso, ainda existem as Mudanças Climáticas: o mais grave dos problemas ambientais a ser enfrentado pela humanidade neste século. A mudança do clima está ligada ao uso de energias não-limpas, processos industriais, e uso do solo, como 
desmatamento, queimadas e pecuária. A mudança do clima chuva em algumas regiões e secas em outras, falta de água, redução da produção de alimentos, entre outros.

Os problemas citados acima têm diversas origens e ocorrem em diferentes momentos da história, sendo em alguns casos acentuados em determinados períodos. Um exemplo: o homem sempre explorou recursos naturais para manter sua sobrevivência e esta exploração sempre causou impactos. Porém, na atualidade devido ao aumento da população (segundo a ONU crescemos em média 1 bilhão de habitantes a cada 12 anos) e ao modelo de produção e consumo adotado pela atual civilização, esses impactos ocorrem em larga escala, causando problemas ambientais sem precedentes - como o esgotamento dos recursos naturais e o aquecimento global.

Um dos impactos gerados pelo ser humano é a utilização de motores à combustão, a grande utilização dos veículos motorizados, por exemplo, grandes emissores de gases poluentes na atmosfera. De acordo com Andres ET. AL. (1996) apud Dias (2002), no momento, cerca de $80 \%$ da emissão anual de CO2 para a atmosfera ocorre em função da queima de combustíveis fósseis (carvão e derivados do petróleo).

Embora a utilização de combustíveis fósseis seja crucial para o desequilíbrio do orçamento global do carbono e esse desequilíbrio contribua para o efeito estufa, e este para as alterações climáticas globais, nas condições atuais, em diversas situações, seria impossível deixar de utilizar essa forma de combustível de uma hora para outra. O Corpo de Bombeiros do Estado do Paraná encontra-se nessa situação, tendo em vista a necessidade de viaturas de grande porte e potência para atender as necessidades do serviço requisitado, porém, existem algumas medidas que podem reduzir o impacto causado, as quais serão aclaradas posteriormente.

Enquanto um veículo bem regulado libera uma taxa x de gás carbônico (CO2) motores com excesso de combustível e deficiência de oxigênio na mistura e resultam em combustões incompletas, com liberação de monóxido de carbono (CO). Quando a mistura de ar combustível, tem pouco O2, os hidrocarbonetos são apenas oxidados 
para $\mathrm{CO}$, sendo exaustados. Ainda quando há mais o2 disponível, o N2 é transformado em óxido de nitrogênio.

Baird (2004) cita que grande parte dos problemas de poluição do ar nas cidades origina-se das emissões dos motores movidos a gasolina, e de que os combustíveis fósseis quando queimados produzem grande quantidade de gases indutores do efeito estufa:

"Por essas razões, a atenção está se voltando para o desenvolvimento de fontes alternativas de combustíveis de combustão mais limpa. Algumas dessas alternativas são também renováveis, no sentido de que sua produção pode ser sustentada por tempo indeferido no futuro sem que isso resulte na acumulação de grandes quantidades adicionais de dióxido de carbono. Isto é importante dado que uma fração significativa da energia mundial é usada para o transporte". (BAIRD, 2004, p.274)

Para analisar até que ponto a ação do influência no meio ambiente Johnson (1994) apud Dias (2002) anuncia que cortadores de grama com motor movido a gasolina respondem a 5\% de toda a poluição atmosférica dos Estados Unidos. Esses pequenos e ineficientes motores de 3,5 hp emitem, em duas horas de atuação, a mesma quantidade de hidrocarbonetos emitidos por um carro novo percorrendo $4.830 \mathrm{~km}$. Na maioria dos quartéis de Bombeiros os cortadores de grama são movidos a gasolina. O grande desperdício de energia elétrica é outra forma de impacto ao meio ambiente. A energia elétrica é vista como algo em disponibilidade eterna e praticamente sem custos ambientais e raramente faz parte da preocupação das pessoas, e por isso ocorre o desperdício. Segundo o Procel (Programa de Conservação de Energia Elétrica, Ministério da Indústria e Comércio), o Brasil desperdiça em torno de 18\% da energia produzida. $O$ país perde 5 bilhões de dólares anualmente devido a equipamentos obsoletos, máquinas desreguladas, banhos demorados e luzes acesas desnecessariamente. Podemos ainda citar o fato do uso do chuveiro elétrico equipamento usado em pouquíssimos países e altamente dispendioso ou, então, televisão ligada sem telespectadores, ar-condicionado em exagero, geladeiras

Disponível em: https://www.nucleodoconhecimento.com.br/meio-ambiente/importancia-da- 
abertas por muito tempo ou com vedação ineficaz, utilização de lâmpadas amarelas, etc. Fatos comumente observados nos quartéis do Corpo de Bombeiros.

"O provimento de energia elétrica no Brasil é oriundo em sua maioria, de usinas hidroelétricas. Logo, o consumo de eletricidade acaba contribuindo também para o estabelecimento de impactos ambientais negativos gerados pela instalação, operação e manutenção dessas usinas" (DIAS, 2002, p.154).

Os efeitos que Dias (2002) faz referência são:

- Impedimento à migração de peixes;

- Modificação do teor de oxigênio dissolvido na água (anoxia);

- Proliferação de macrófitas aquáticas;

- Aumento do teor de nutrientes sólidos, materiais flutuantes e húmicos²;

- Diminuição do transporte de sedimentos a jusante;

- Mortandade de organismos aquáticos;

- Alteração na paisagem natural;

- Instabilidade das margens;

- Desflorestamentos;

- Drástica redução no estoque pesqueiro nativo,

Na maioria das vezes o Bombeiro Militar não possui conhecimento das consequências que seus hábitos podem causar, como o simples fato de deixar a luz do alojamento acesa ao sair para uma ocorrência, por exemplo.

O consumo desenfreado de água também representa uma preocupação. "A água é um fator limitante vital para as espécies que vivem na Terra. A espécie humana, apesar de todo o progresso científico e tecnológico, não consegue viver sem esse componente ecossistêmico". (DIAS, 2002,p.155). 
Da água existente no planeta, $97 \%$ são mares e apenas 3\% são de água doce. Ainda, desses $3 \%, 76 \%$ encontram-se sob a forma de gelo, restando, apenas $0,03 \%$, dos quais grandes partes encontram-se na forma águas subterrâneas.

Dados do Programa das Nações Unidas para Desenvolvimentos (PNUD) ${ }^{3}$ retratam os aspectos da escassez de água potável: Mais de 1 bilhão não têm acesso à água potável. Isso gera doenças que matam milhões de pessoas todos os anos. Cinco milhões de habitantes, a maioria crianças, morrem anualmente por conta de doenças relacionadas à qualidade da água. Além disso, mais de $50 \%$ dos africanos sofrem de doenças relacionadas à qualidade da água, como cólera e diarreia infantil.

Apesar de o Brasil possuir em torno de $12 \%$ das reservas de água do mundo, não justifica um uso desenfreado da mesma. Pelo contrário, significa que temos que cuidar ainda mais.

Segundo Gonçalves, (1998), um fator agravante ao desperdício de água é a má utilização de água tratada para a higiene, indústria, comércio, alimentação, lazer e manutenção, chegando a um expressivo volume de $30 \%$ da água tratada. Podendo adicionar as perdas na rede física, por vazamento e outros fatores que chegam a $28 \%$.

Além da má utilização da água, outros fatores causados pelos humanos também interferem sobre a natureza de forma negativa, como o consumo excessivo de papel e madeira.

De acordo com o Instituto Brasileiro de Defesa do Consumidor (IDEC), o papel continua na lista dos produtos de maior impacto ambiental. Para produzir uma tonelada de papel são necessárias cerca de 2 a 3 toneladas de madeira, uma quantidade expressiva de água (excedendo a quantidade utilizada em qualquer outra atividade industrial) e muita energia (por isso, essa ocupa o quinto lugar na lista das indústrias que mais consomem energia). São utilizados, também, produtos químicos altamente tóxicos nos processos de separação e branqueamento da celulose, os quais vêm a representar um sério risco para a saúde humana e para o meio ambiente 
- comprometendo a água, o solo e os alimentos produzidos aos arredores dessas indústrias.

Para contornar a situação, várias saídas têm sido apontadas como a utilização de madeira de reflorestamento ou como a redução do emprego de cloro nos processos de fabricação e reciclagem. Porém, ainda se está longe de alcançar uma produção limpa e sustentável.

A reciclagem do papel e do papelão não só ajuda a reduzir o volume de lixo como evita a derrubada de árvores. De acordo com o IDEC, no Brasil, o contingente de papel que culmina nos processos de reciclagem mal chega aos $37 \%$, dos quais, considerados como categoria descartável, $80 \%$ são destinados à confecção de embalagens, $18 \%$ para papéis de uso sanitário e higiênico e apenas $2 \%$ para a impressão.

O aquecimento global é outro problema que acelera a perda de reserva de água potável do planeta. A liberação excessiva de gases reforça o efeito estufa, o responsável pelo aquecimento da atmosfera, aumentando a temperatura da Terra e com isso contribuindo para o derretimento de geleiras. De acordo com a Revista GE em pouco mais de dez anos o derretimento no Ártico dobrou, enquanto os Alpes perderam $50 \%$ da sua cobertura gelada em meio século. Além da perda de reserva de água potável, outro problema acarretado por consequência do derretimento do gelo, e ainda mais preocupante, é a elevação do nível dos oceanos.

Várias espécies da flora brasileira já estão ameaçadas de extinção, somam-se mais de 300 espécies em risco. A fauna não se encontra em melhores condições. Mamíferos vêm ameaçados por caça ilegal e por degradação ambiental com destruição de habitats. Esse quadro se estende por todo o planeta. Peixes e pássaros também se incluem no desastre referente à fauna. De acordo com a revista GE por causa das barragens dois terços dos 177 maiores rios do globo não fluem mais livremente até o mar, somando com a poluição mais de 3 mil espécies aquáticas estão ameaçadas de extinção. Quanto aos pássaros sua principal ameaça é a destruição 
de seus habitats e com isso, a destruição de seus espaços de reprodução. No Brasil são mais de 100 espécies sob risco de extinção.

\subsection{DESENVOLVIMENTO SUSTENTÁVEL E SUSTENTABILIDADE}

Por muitos anos o crescimento desenfreado do desenvolvimento industrial e populacional não demonstrou o impacto ambiental que, aos poucos, causava na natureza, a própria população acreditava tê-la como recurso eterno, inesgotável. Mas, ao longo do tempo alguns delitos foram se tornando preocupantes. A grande produção de lixo (tóxicos, de degradação lenta, etc.), a poluição da atmosfera, rios e solos, o desmatamento de matas ciliares, o plantio de espécies invasora sem matas, etc., só colaboraram mais ainda para a perda de muitos recursos naturais existentes. No ano de 1987, na tentativa de alertar o problema, de maneira que a sociedades contínuas se a evoluir, porém sem causar impactos ambientais de grande magnitude, foi publicado o relatório "Nosso Futuro Comum", mais conhecido com o "Relatório Brundtland", onde o Desenvolvimento Sustentável foi proposto como a melhor alternativa de modelo de desenvolvimento a ser adotado pela sociedade, sendo definido como:

Por muitos anos o crescimento desenfreado: "Aquele que atende às necessidades do presente sem comprometer a possibilidade de as gerações futuras de atenderem as suas próprias necessidades" (COMISSÃO BRUNDTLAND apud ACSELRAD; LEROY, 1994, p.17).

Baseado no conceito supracitado, Valle (1995) desfragmenta, ainda, outros dois conceitos: onde o primeiro é o conceito das necessidades, que podem variar de sociedade para sociedade, mas que devem ser satisfeitas para assegurar as condições essenciais de vida a todos, sem distinções. O segundo conceito é o de limitação, que reconhece a necessidade de a tecnologia desenvolver soluções que conservem os recursos limitados atualmente disponíveis e permitam renová-los na medida em que eles sejam necessários às gerações futuras. 
Há, ainda, autores que acreditam que a Comissão de Brundtland (1987) evita a problemática da redução de padrões de consumo pelos países (ditos) desenvolvidos. Alegando serem esses padrões insustentáveis, galgando então a rumos opostos do proposto. Layrargues (1997) comprova isso ao propor que deveria ser estabelecida uma linha mediana entre os países desenvolvidos e subdesenvolvidos, atendendo às necessidades básicas dos povos, obtendo um teto de consumo material que limita os impactos causados ao meio ambiente. Relacionando assim o desenvolvimento sustentável à ideologia neoliberal.

Sendo assim, a proposta de desenvolvimento sustentável apresenta uma forma de abordagem inspirada em diferentes formas de exploração dos recursos naturais, na implementação de tecnologias "limpas" e na mudança de manejo do meio ambiente.

Para IUCN, Pnuma, WWF apud Dias (2001) o desenvolvimento sustentável pode ser descrito como "melhorar a qualidade de vida humana dentro dos limites da capacidade de suporte dos ecossistemas".

\subsubsection{NECESSIDADE DE MUDANÇA}

A partir do momento em que o homem tomou o mínimo de consciência sobre suas atitudes, a sociedade a passos lentos, mas objetivados, vem mudando. A sociedade está adotando uma nova postura frente ao tema "produção e consumo" associado a "consciência ambiental". Termos que há algumas décadas nem haviam sido pronunciados tornam-se frequentes no dia-a-dia das pessoas e, de certa forma, já são uma realidade para as crianças.

Um exemplo de mudança desse paradigma é que há alguns anos quando se falava em preservação do meio pensava-se em não jogar um saco plástico na rua, hoje já se tem a preocupação de nem sequer adquirir o saco plástico. "O desenvolvimento sustentável leva a uma economia sustentável. A preservação e o aproveitamento racional dos recursos naturais são conseguidos pelo desenvolvimento sustentável, possibilitando a viabilidade da economia sustentável e dando ao homem um ambiente saudável". (CHIAVENATO, 1997, p.113).

Disponível em: https://www.nucleodoconhecimento.com.br/meio-ambiente/importancia-daaplicacao 
Um caminho é a Atuação Responsável. Este termo surgiu no Canadá, na década de 80 , teve origem na indústria química para que esta resgatasse, em parte, a imagem negativa que vinha acumulando havia décadas.

"As soluções para os problemas ambientais, trazidos pela Atuação Responsável, são de enfoque proativo, antecipando à legislação, e ao mesmo tempo sua visão sistêmica abarca, em um mesmo programa, preocupações com segurança, saúde ocupacional e meio ambiente" (VALLE, 1995, p.11).

O programa de atuação responsável proposto por Valle (1995) é constituído por cinco elementos:

1. Princípios diretivos - estabelecimento dos princípios em que devem basear suas ações para atingir os objetivos propostos;

2. Códigos gerenciais - são os padrões de desempenho que devem ser atingidos pela empresa, no caso, no que se refere à prevenção de riscos ambientais;

3. Conselho comunitário consultivo - estabelece as regras de convivência da empresa com a comunidade;

4. Grupos de liderança executiva - reunião de líderes das sub-divisões da empresa para avaliar as experiências acumuladas no processo;

5. Auto-avaliação - possibilita a empresa avaliar os sucessos alcançados, à luz de suas próprias condições e culturas internas, estabelecendo novas metas e objetivos que se incorporarão aos códigos gerenciais.

Após executar uma estruturação eficaz de atuação responsável perante o Meio Ambiente algumas condições são necessárias, como afirma Valle (1995) para que se mantenha o equilíbrio entre a empresa, a comunidade e legislação ambiental alguns requisitos são indispensáveis (só serão citadas as afirmações cabíveis ao Corpo de Bombeiros como empresa):

a) A empresa deve expressar claramente seu compromisso com a Qualidade Ambiental e tornar público os princípios estabelecidos em sua Política Ambiental. 
b) Os objetivos a atingir e resultados devem ser postos à disposição de interessados. Posicionando-se sempre de maneira receptiva a críticas e sugestões.

c) Demonstrar comprometimento e competência na solução de seus problemas com resíduos e no controle de suas fontes de poluição, sempre que necessário recorrendo às novas tecnologias e organismos de pesquisa.

d) Colaborar com autoridades responsáveis pela qualidade de meio ambiente da região, podendo até realizar projetos em

e) Estar apto para contribuir no controle de ocorrências e acidentes ambientais quando

Pode-se observar a incumbência, por parte da Corporação, no processo pela Lei no 9.795, de 27 de abril de 1999, Capítulo I - Da Educação Ambiental, a qual cita no Art. $3^{\circ}$ "Como parte do processo educativo mais amplo, todos têm direito à educação ambiental, incumbindo: $V$ - às empresas, entidades de classe, instituições públicas e privadas promover programas destinados à capacitação dos trabalhadores, visando à melhoria e ao controle efetivo sobre o ambiente de trabalho, bem como as repercussões do processo produtivo do meio". Mudanças são necessárias e importantes para a conservação do nosso meio ambiente. No citado acima se encontra destacado o termo 'instituições públicas' e com isso inclui-se, e observa-se que não isento de obrigações para com o meio ambiente, o Corpo de Bombeiros do Estado do Paraná.

Ainda como observado no Tratado de Educação Ambiental para Sociedades Sustentáveis e Responsabilidade Global (1992), temos no $1^{\circ}$ princípio: "A Educação Ambiental é um direito de todos; somos todos aprendizes e educadores", onde mais uma vez é colocada a responsabilidade no âmbito geral, de todos, incluindo o Corpo de Bombeiros como, também, órgão responsável.

Somando os tais fatores supracitados cabe elevar o fato da confiabilidade da população no Corpo de Bombeiros, em pesquisa realizada pelo Jornal Gazeta do Povo de 13 de Janeiro de 2008, na cidade de Curitiba, onde o objetivo era identificar

Disponível em: https://www.nucleodoconhecimento.com.br/meio-ambiente/importancia-da- 
as instituições de maior credibilidade, o Corpo de Bombeiros é campeão para os curitibanos, com índice de 97\%, índice este que se encontra a frente de diversos outros órgãos como, por exemplo, a própria prefeitura da cidade, Forças Armadas e Igrejas. Ainda analisadas as profissões os bombeiros encontram-se com o maior índice, seguido, com mais de $5 \%$ de diferença, de professores e enfermeiros. Considerando esses fatores torna-se clara a relação existente entre a população e o Corpo de Bombeiros, e por existir esse tão elevado grau de confiança é necessário que no âmbito ambiental exista uma preocupação para dar em resposta à sociedade.

O Corpo de Bombeiros por possuir todo esse respeito não pode manter-se indiferente em questões tão atuais e importantes. Ao instante que a população possuir o conhecimento de práticas positivas, na questão do desenvolvimento sustentável, por parte do Corpo de Bombeiros, esta terá mais esse incentivo de mudança, além de aumentar seu carisma pela profissão, o que proporcionará à Corporação aumento de credibilidade. Os próprios bombeiros perante seus familiares e vizinhança demonstrarão atitudes exemplares e que serão aos poucos adotadas por mais pessoas.

O Corpo de Bombeiros deve reconhecer a gestão ambiental entre umas das mais altas prioridades a serem geradas e como um determinante-chave do desenvolvimento sustentável, com elaboração de políticas, programas e práticas para conduzir suas operações de maneira que impactem menos o meio ambiente. Após a implementação de atividades visando à melhoria da questão ambiental na corporação, esta deve medir, monitorar e avaliar seu processo ambiental.

Para que todas essas mudanças ocorram são necessários vários estudos, com a realização de projetos que visem mudança nas estruturas das dependências dos quartéis operacionais, bem como nas dependências das sessões administrativas. 


\subsubsection{AS SOLUÇÕES}

\subsubsection{EDUCAÇÃO AMBIENTAL}

A Educação Ambiental para Pedrini (1997) seria o processo no qual deveria ocorrer um desenvolvimento progressivo de um senso de preocupação com o meio ambiente, baseado num completo e sensível entendimento das relações do homem com o ambiente a sua volta. "É um processo de formação e informação orientado para o desenvolvimento da consciência crítica sobre as questões ambientais, e de atividades que levem à participação das comunidades na preservação do equilíbrio ambiental. (CONAMA, 1989, p.28)"

Esse processo de reconhecimento de valores é que possibilitará a tomada de atitudes necessárias para que ocorra o desenvolvimento de habilidades para possibilitar a coexistência do homem, sua cultura e seu ambiente. Dias (2003) demonstra a relevância de inserir um programa de Educação Ambiental para o cidadão comum, onde cabe inserir os integrantes do Corpo de Bombeiros:

"Oferece orientação aos governos, estabelece o Plano de Ação Mundial, e, em particular, recomenda que seja estabelecido um programa internacional de Educação Ambiental visando educar o cidadão comum, para que maneje e controle seu ambiente. A recomendação no96 reconhece o desenvolvimento da Educação Ambiental como elemento crítico para o combate à crise ambiental no mundo" (DIAS, 2003,p.36).

Ao realizar Educação Ambiental, é essencial elaborar um processo que consista em propiciar às pessoas uma compreensão crítica e global do ambiente, para elucidar valores e desenvolver atitudes que lhe permitam adotar uma posição consciente e participativa, a respeito das questões relacionadas com a conservação e adequada utilização dos recursos naturais, para a melhoria da qualidade de vida e a eliminação da pobreza extrema e do consumismo desenfreado. 
Como consta na Lei no 9.795, de 27 de abril de 1999, Capítulo I - Da Educação Ambiental, Art. $2^{\circ}$ "A educação ambiental é um componente essencial e permanente da educação nacional, devendo estar presente, de forma articulada, em todos os níveis e modalidades do processo educativo, em caráter formal e não-formal". A educação ambiental deve ser proposta nos cursos de formação contidos no Corpo de Bombeiros, principalmente nos cursos de entrada para a corporação, como é o caso do Curso de Formação de Soldados e Curso de Formação de Oficiais.

Também deverão ser realizadas palestras, instruções e discussões durante todo o ano, com objetivo de demonstrar a importância da atuação unitária e a repercussão positiva dessa mudança perante a população. Distribuição interna de cartazes e folders contendo informações de como agir em diversas situações com o objetivo de proporcionar mais segurança ao meio ambiente, de como com pequenas atitudes pode-se avançar a uma elevada etapa de conscientização e maior preservação. De nada adianta a mudança estrutural se não adequar os usuários para que possam dar continuidade a essa mudança.

Dias (2001) acentua que "a Educação Ambiental deve dirigir-se a pessoas de todas as idades, a todos os níveis, na educação formal e não-formal". Isto é, no público em geral, composto por jovens e adultos, cujos comportamentos cotidianos têm uma influência decisiva na conservação do meio ambiente.

É necessário que os homens compreendam que "não fazer nada, porque não se pode mudar tudo o que está mal, é uma atitude irresponsável", Muller (1975) apud Dias (1991). A partir do momento que uma coisa muda, um todo começa a mudar.

Seria interessante propor que cada integrante do Corpo de Bombeiro colocasse em um papel uma frase expressando a sua contribuição pessoal para a redução do consumo dos recursos naturais. E demonstrar que atitudes simples podem fazer diferença:

“[...] como economizar energia elétrica ao apagar uma lâmpada, evitar que a porta da geladeira fique aberta por muito tempo, tomar banho

Disponível em: https://www.nucleodoconhecimento.com.br/meio-ambiente/importancia-daaplicacao 
menos demorados, dar preferência a produtos biodegradáveis, recicláveis e que não utilizem embalagem plástica, jogar lixo nos locais adequados, zelar pelo patrimônio cultural, evitar o desperdício de água, manter o patrimônio público, plantar árvores e zelar pela vegetação urbana, informar-se a respeito das questões ambientais da sua cidade, participar de eventos comunitários, etc."(DIAS, 1991, p.329).

A principal das questões a ser abordada perante a instituição deve ser a sensibilização/conscientização. "O processo de sensibilização tem o potencial de preparar as pessoas para as mudanças" para Dias (2001).

Na Constituição da República Federativa do Brasil (1988) o seu artigo 225 determina:

"Todos têm o direito ao meio ambiente ecologicamente equilibrado, bem de uso comum do povo essencial à sadia qualidade de vida, impondo-se ao Poder Público e à coletividade o dever de defendê-lo e preservá-lo, para as presentes e futuras gerações" (CONSTITUIÇÃO DA REPÚBLICA FEDERATIVA DO BRASIL, 1988).

\subsubsection{ATITUDE COMPORTAMENTAIS}

A seguir serão citadas várias atitudes que devem ser, por meio da Educação Ambiental, esclarecidas e apresentadas aos bombeiros, para que estes possam inseri-las em seus hábitos diários, e comprometendo-se a ser um multiplicador de atitudes sustentáveis, gerando qualidade de vida e preservando o meio ambiente.

Um dos hábitos a serem inseridos deve ser a preocupação com a produção de lixo. A minimização do lixo de inúmeras formas pode ser efetuada. Um exemplo é fazer com que haja um planejamento detalhado para que não sejam adquiridos materiais desnecessários. Que em um futuro podem não ter utilidade e, consequentemente, tornarão lixo. A utilização de um produto durante toda a sua vida útil, também é de suma importância. 
Para, por exemplo, minimizar a geração de garrafas plásticas durante a Operação Verão ${ }^{4}$, cada militar poderia receber sua própria garrafa de alumínio, ou

Cantil, e abastecê-lo nos filtros do quartel. Outro exemplo que já vem sendo adotado em alguns quartéis é a utilização de canecas pessoais objetivando a redução de copos plásticos descartáveis.

Outra forma de se preocupar com a produção do lixo é a redução do consumo de papel. O Instituto Brasileiro de Defesa ao Consumidor aponta algumas atitudes que auxiliam nessa redução:

Outra forma de se preocupar com a produção do lixo é a redução do consumo de papel. O Instituto Brasileiro de Defesa ao Consumidor aponta algumas atitudes que auxiliam nessa redução:

- Evitar comprar produtos com excesso de embalagens;

- Ao imprimir ou escrever, utilizar ambos os lados do papel;

- Revisar textos na tela do computador e só imprimir se realmente for necessário;

- Dar preferência a produtos reciclados ou aqueles que trazem o selo de certificação do FSC (Conselho Brasileiro de Manejo Florestal -Brasil);

- Separar o lixo;

- Em licitações observar as empresas quanto o seu comprometimento com o desenvolvimento sustentável, se for o caso, se possui o FSC;

- Instalar secador de mãos em toillets e afins;

- Utilizar arquivos digitais;

- Utilizar meios eletrônicos para envio de documentos, como via e-mail.

Tratando de redução de emissão de gases poluentes o Instituto Akatu pelo Consumo Consciente afirma existirem várias atitudes que podem contribuir para a redução, serão para essas adicionados termos utilizados no Corpo de Bombeiros para facilitar a compreensão: 
- Manutenção de viaturas - realizar revisões periódicas no veículo para reduzir a emissão dos poluentes e calibrar pneus;

- Criar e incentivar o "Dia Voluntário Sem Carros" e incentivo às bicicletas;

- Incentivar o uso de transporte coletivo - caronas;

- Optar por viaturas movidas a álcool, biodiesel ou bicombustíveis.

Abordando a questão de redução desperdício de água a Organização Rede das Águas (2004) cita alguns processos simples que podem ser feitos:

- Ao banho: molhar-se, fechar o chuveiro para ensaboar-se e posteriormente ligá-lo para o enxágue, com isso o consumo cairá de 180 para 48 litros;

- Ao escovar os dentes enxaguar a boca com água de um copo;

- Verificar se não existe defeito na válvula de descarga, apertá-la uma única vez, não jogar lixo e restos de comida no vaso;

- Fechar bem as torneiras, verificar a existência de vazamentos;

- Ao lavar a louça ensaboar a mesma com a torneira fechada e enxaguar tudo de uma única vez;

- Lavar viaturas com mangueira são gastos 600 litros d'água enquanto que com balde são gastos apenas 10 litros para ensaboar e enxaguar;

- Em demais limpezas priorizar a vassoura, utilizando água somente quando necessário.

\subsubsection{SOLUÇÕES ESTRUTURAIS}

Para Baird (2004) "a energia solar é uma excelente fonte de calor para temperaturas próximas ou inferiores ao ponto de ebulição da água, uma categoria que contribui com mais da metade do consumo de energia". Mesmo em ambientes de clima temperado, durante o inverno, existem processos onde pode-se absorver a energia.

Ainda em sistemas melhores elaborados a água quente circula através de um trocador de calor, que é um sistema de tubos sobre os quais o ar é forçado a passar e consequentemente é aquecido por transferência de calor; esse ar aquecido pode ser 
usado, como é normalmente, para aquecimento interno das edificações no inverno. Nesse caso o calor pode também ser estocado por meio de rochas.

De acordo com Baird (2004), em análises feitas, foram detectadas uma série de vantagens que a energia solar pode apresentar:

- Ela é livre e fantasticamente abundante;

- Apresenta baixo impacto ambiental;

- Seus custos operacionais são baixos;

- Não requer fornecedores centralizados (Ex: Copel, etc.) e de grande porte e redes de distribuição caras;

- Pode até requerer um alto capital para a construção do sistema de coleta e armazenamento, porém, é compensado pela natureza livre da energia por algum tempo até a amortização do investimento;

A Universidade Federal de São Carlos em seu site cita dicas para economizar energia em um escritório, o que pode ser realizado nos serviços administrativos da Corporação:

- Instalar iluminação acionada por meio de sensores ou iluminação natural;

- Preferência do ventilador ao ar-condicionado;

- Utilizar lâmpadas frias,

Valle (1995) cita o reaproveitamento da água como um dos exemplos de aplicação de tecnologias limpas.

Outra forma de cuidar da água é realizando o reaproveitamento. A água utilizada nas pias, chuveiros e máquinas de lavar roupa - representam $50 \%$ da água utilizada por uma pessoa são consideradas "limpas" e depois de passarem por um sistema pode ser utilizada em diversas situações como enchimento de viaturas de combate a incêndio, enchimento de bomba costal, lavagem das dependências do quartel, na descarga, etc. No sistema de reaproveitamento essa água não mais se juntará ao esgoto comum. Seu primeiro destino será a caixa de gordura. Para Chahin (1999) a 
construção de uma caixa de gordura é essencial para que a água possa ser reaproveitada. Os esgotos contêm grande acúmulo de substâncias como óleos, ceras, graxas, gorduras, entre outros materiais de densidade característica inferior à da água. As caixas de gordura são as unidades de remoção desses materiais de densidade menor que a da água.

O segundo passo para reaproveitamento da água é a desinfecção que consiste em uma forma de extermínio de organismos patogênicos, como relata Chahin (1999). cloro, agente desinfetante em questão, tem a função de penetrar nas cédulas dos microrganismos e reagir diretamente com suas enzimas e, por fim, destruí-las. As enzimas são, basicamente, um complexo de proteínas especializadas que funcionam como catalisadores orgânicos em reações químicas dos microrganismos. Como são essenciais aos processos metabólicos das células vivas, estas, sem a ação das enzimas, morrem.

Depois desse processo a água deve ser bombeada para um reservatório, onde será requisitada para os devidos fins. Chahin (1999) garante que a construção desse sistema pagará a si mesmo em torno de dois anos, com a economia de água.

\section{CONSIDERAÇÕES FINAIS}

Por meio dos dados bibliográficos agrupados e de entendimento de seu conteúdo, analisadas as leis e propostas para uma caminhada em direção ao desenvolvimento sustentável percebe-se que o objetivo proposto inicialmente foi esclarecido. Foi possível observar que o enfoque do desenvolvimento sustentável e da educação ambiental se encontram cada vez mais em elevada importância, são inúmeras nações preocupadas com o futuro do Planeta. Cada vez surgem mais ideias que procuram amenizar os danos causados pelos humanos ao planeta.

Foi permitido constatar, então, a real importância de iniciar uma nova proposta que possibilite a inserção de métodos educacionais aos bombeiros, desde o momento de sua entrada na corporação, como durante processos de instrução visando uma reciclagem de ideias. Por meio desse pensamento, associado a educação ambiental

Disponível em: https://www.nucleodoconhecimento.com.br/meio-ambiente/importancia-da- 
visa-se atingir um número bem maior de pessoas e atitudes, vez que ao implantar uma ideia ao bombeiro, o mesmo passará a influenciar tantas outras pessoas. Em algumas fundamentações teóricas observamos, também, que são necessárias mudanças no âmbito estrutural, com elaboração de novos projetos que tanto valorizem o meio ambiente, quanto visem degradá-lo o mínimo possível, com políticas de reutilização de materiais, de execução das devidas manutenções de viaturas, de utilização da água de maneira mais adequada possível, com a consciência da importância de sua economia (esta que é um bem tão importante para a Corporação, e um fator de segurança do bombeiro).

Observando o trabalho pelo todo, pudemos perceber que este é apenas uma pequena pauta sobre o vasto assunto, podendo ser apurados novos contextos e aplicações do desenvolvimento sustentável que possam contribuir com a melhoria da Corporação. Com a elaboração de programas que visem solucionar a questão no Corpo de Bombeiros, tornando-o ainda mais bem quisto pela população.

No apanhado geral fica explicita a necessidade de uma renovação ideológica, educacional, estrutural a ser aplicada ao Corpo de Bombeiros do Estado do Paraná, com o simples objetivo de tentar proporcionar à natureza uma mínima devolução tudo aquilo que nos foi emprestado.

\section{REFERÊNCIA}

BAIRD, C. Química Ambiental. Western Ontario: Ed. Bookman, 2004.

CHAHIN, R. R., NetTO, C. A. M. F., MESSUtI, E., RIBEIRO, L. A., Sistema de Reaproveitamento de Água para Edificações.

CHIAVENATO, I. Recursos Humanos: Edição Compacta. São Paulo: Ed. Atlas, 1997.

DIAS, G. F., Educação Ambiental: princípios e práticas. São Paulo: Ed. Gaia, 2001.

Disponível em: https://www.nucleodoconhecimento.com.br/meio-ambiente/importancia-da- 
DIAS, G. F., Pegada ecológica e sustentabilidade humana. São Paulo: Ed. Gaia, 2002.

DIAS, G. F., Educação Ambiental. São Paulo: Ed. Gaia, 2003.

GUIA DO ESTUDANTE, Edição 3, Ed Abril, 2010.

GONÇALVES, E. Metodologias para controle de perdas em sistemas de distribuição de água. Brasília: Universidade de Brasília, Faculdade de Tecnologia, Departamento de Engenharia Brasília, 1998.

INSTITUTO AKATU: pelo consumo consciente. Disponíovel em: HTTP://www.akatu.org.br, consultado em: 21/10/2019.

INSTITUTO BRASILEIRO DE DEFESA DO CONSUMIDOR. Disponível em: HTTP://www.idec.org.br/rev_servicosambientais.asp, consultado em 21/10/2019.

JOLLIVET, M., PAVÉ, A. Gestão de Recursos Naturais Renováveis e Desenvolvimento: Novos Desafios para a Pesquisa Ambiental. São Paulo: Ed. Cortez, 2000.

LAYRARGUES, P. P. Do Ecodesenvolvimento ao Desenvolvimento Sustentável: evolução de um conceito? São Paulo, 1997.

LOURENÇO, M. S., CHIARAMONTI, C. O Desenvolvimento Sustentável e a Economia Circular: A experiência Chinesa. Disponível em: HTTP://www.fae.edu/publicacoes/pdf/lseminario, consultado em: 15/11/2019.

ODUM, E. P. Ecologia. Rio de Janeiro: Ed. Interamericana, 1985.

ORGANIZAÇÃO REDES DE ÁGUAS, disponível em: HTTP://www.rededasaguas.org.br/acesso/itu/dez.htm, consultado em 17/11/2019.

PEDRINI, A. Educação Ambiental - Reflexões e Práticas Contemporâneas. Rio de Janeiro: Ed. Vozes, 1997.

Disponível em: https://www.nucleodoconhecimento.com.br/meio-ambiente/importancia-daaplicacao 
SACHS, I. Espaços, Tempos e Estratégias do Desenvolvimento. São Paulo: Ed. Vértice, 1986.

\section{APÊNDICE - REFERÊNCIAS DE NOTA DE RODAPÉ}

1. Teoria desenvolvida no início da década de 90 pelos especialistas William Rees e Mathis Wackernagel. A Pegada Ecológica foi criada para dimensionar o quanto de recursos da Natureza os seres humanos utilizam para garantir seu consumo. A Pegada Ecológica não é uma medida exata, mas sim uma estimativa de que, até que ponto o estilo de vida dos seres humanos é compatível com a capacidade do planeta de oferecer, renovar seus recursos naturais e absorver resíduos. A Pegada Ecológica leva em conta: (1) as áreas de Terra Bioprodutiva (usada para colheita, pastoreio, corte de madeira e outras atividades de grande impacto); (2) Mar Bioprodutivo (área necessária para pesca e extrativismo); (3) Terra de Energia (área de florestas e mar necessária para a absorção de emissões de carbono; (4) Terra Construída (área para casas, construções, estradas e infra-estrutura); Terra de Biodiversidade (áreas de terra e água destinadas à preservação da biodiversidade)(http://www.wwf.org.br/wwf_brasil/pegada_ecologica/).

2. Decomposição dos vegetais submersos com a consequente produção de gás sulfídrico e amônia.

3. Números divulgados a partir de estudos feitos para o Projeto do Milênio, criado pela Organização das Nações Unidas, em 2002,para desenvolver um plano de ação como objetivo de reverter o quadro de pobreza, fome e doenças opressivas que afetam bilhões de pessoas. O Projeto do Milênio é um órgão consultivo independente que lançou, em 2005, um plano global para alcançar os Objetivos de Desenvolvimento do Milênio (http://www.pnud.org.br/milenio/index.php).

4. Operação realizada normalmente no período de dezembro a março com o objetivo de deslocar policiais militares, civis, bombeiros militares, entre outros profissionais, ao litoral do Paraná a fim de guarnecer a região, devido ao drástico aumento populacional.

Disponível em: https://www.nucleodoconhecimento.com.br/meio-ambiente/importancia-da- 
Enviado: Outubro, 2019.

Aprovado: Janeiro, 2020. 